\title{
3D visualization of the results of using modern OFA technology on the example of real boiler
}

\author{
ASKAROVA A.S., BOLEGENOVA S.A., BOLEGENOVA S.A., MAXIMOV V.YU., \\ BEKETAYEVA M.T. \\ Physics and Technology Faculty \\ Al-Farabi Kazakh national university \\ Almaty, Al-Farabi av., 71 \\ REPUBLIC OF KAZAKHSTAN
}

\begin{abstract}
The leading place in the world for environmental protection is currently occupied by the protection of the air basin. And the main sources of atmospheric pollution are industrial enterprises, motor transport and thermal power plants. Thus, there is an obvious need to increase attention to the problems of the innovation sector, mainly in the areas of technical improvement of heat and power industry enterprises. Therefore, the study of the problems of reducing the amount of harmful emissions into the atmosphere, control and regulation of its quality, as well as the study of new various methods of innovative development of thermal power is an urgent task at present, requiring a serious scientific approach. In the proposed work, computer experiments were carried out in the field of innovative energy production technologies (the use of modern "sharp blast" OFA technology) at a specific thermal power facility of the enterprise of the Republic of Kazakhstan. During the experiment, various ways of supplying additional air through OFA nozzles were investigated: OFA $=0 \%$ (basic version without additional air supply), $\mathrm{OFA}=10 \%$ and $\mathrm{OFA}=18 \%$. For these three modes, a comparative analysis of the aerodynamics of the furnace part of the boiler was performed according to the obtained distributions of the temperature and concentration fields of nitrogen oxide NO over the entire volume of the combustion chamber. The results obtained were compared with experimental data obtained during experiments conducted directly at the CHP.
\end{abstract}

Key-Words: - Coal combustion, emission, modelling, NOx, OFA technology, 3D visualisation

Received: January 5, 2021. Revised: November 25, 2021. Accepted: December 5, 2021. Published: December 20, 2021.

\section{Introduction}

When burning any kind of fuel, the main harm to the atmospheric layers of the Earth is caused by emissions from the exhaust gases of sulfur oxides SOx and nitrogen oxides NOx. Reducing the amount of harmful NOx emissions generated during the combustion of organic fuel at thermal power plants plays a crucial role in reducing the total level of nitrogen oxides NOx emitted into the atmosphere, and therefore it is obvious that reducing their content in the gas emissions of fuel-using installations of thermal power plants is one of the main tasks of scientists and technologists of the world [1-5].

To the greatest extent, the formation of nitric oxide NO is affected by the temperature value. Thus, with its increase from 1500 to $2200 \mathrm{~K}$, about 10 times more nitrogen oxide is formed, while an increase in the concentration of oxygen in a fivefold volume leads to an increase in NO yield by only 2 times.

Nitrogen oxides in the process of burning of organic fuel are formed due to 4 main mechanisms [6]:

"thermal" - according to the Zeldovich chain scheme;

"fast" - by activating molecular nitrogen in reactions with hydrocarbon radicals located in combustion;

"fuel" - by oxidation of compounds with nitrogen contained in the fuel;

the latter mechanism is formation with the help of $\mathrm{N}_{2} \mathrm{O}$, which has an important value at high rates of excess air coefficient.

One of the main methods of suppressing "thermal" and "fuel" NOx is the step-by-step combustion of a pulverized coal mixture, including the "Overfire air" technology. The combustion consists in the fact that less air enters the main combustion area than is 
required at the theoretical level $(\alpha=0.70-0.95)$, and the remaining air supplied for the purpose of complete combustion of fuel is sent further at one or more levels along the height of the torch, resulting in a decrease in the maximum high temperature in the combustion area and the amount of $\mathrm{O}_{2}$ in the core of the torch is reduced, the reactions of $\mathrm{NO}$ formation are slowed down, and the length and luminosity of the torch also increase [7-9].

The distinctive principle of step-by-step combustion is the existence of a reduction zone in which, due to lack of air, incomplete combustion products are formed, and namely carbon monoxide and hydrogen, and nitrogen oxide is not formed at this time. The concentration of nitric oxide in the reduction area decreases during the step-by-step combustion, and as a result of the three-step combustion, $\mathrm{NO}$, which arrived from the oxidation zone, is completely regenerated to $\mathrm{N}_{2}$.

The implementation of step-by-step combustion in combination with the use of low-toxic burners provides an opportunity to effectively reduce the yield of nitrogen oxides to about $75 \%$.

The fuel technology of air supply over the fire (OFA) or it is also called the "sharp blast" technology is a system of deep two-stage combustion of fuel with the supply of secondary or tertiary air into the boiler furnace in order to reduce NOx emissions. The system (OFA) helps to ensure improved mixing of fuel with oxidizer and to create the right setting for optimal boiler performance, as well as to reduce the amount of nitrogen oxide emissions into the atmosphere.

The "sharp blast" (OFA) technology requires the introduction of air into the combustion furnace, which must be divided into primary and secondary flow sections in order to achieve complete burnout and promote the formation of nitrogen, and not NOx. Primary air is some part of all the air needed for burning, supplied for the purpose of preparatory mixing with fuel through burners. The primary air (the $70-90 \%$ of all air) is combined with the fuel, lowering combustion temperature in the combustion chamber to about 400-600 K. Secondary (10-30\%) air - the main part of the burning air is pumped over the combustion zone through a special air box with air supply holes and/or nozzles installed above the burners [10].

As a r esult, oxygen deficiency is formed in the combustion chamber, a fuel-enriched combustion region, therefore, which improves the process of reducing the formation of $\mathrm{NOx}$ from nitrogen contained in the fuel (fuel NOx). Secondary injected ceilings are installed in addition above the combustion by means of special injectors with air ports located in the plane above the main burners.

The positioning of such additional injectors is determined in accordance with the configuration of the combustion chambers. In this area, the main burning process is almost completed.

Thus, the "sharp blast" is injected above the main combustion area into several air channels, which are placed on the front and rear walls of the boiler's combustion chamber from above the level of the main burners, in order to achieve the most complete combustion of fuel. The relatively low temperature in the afterburning area, enriched with oxygen, has the consequence of reducing the formation of nitrogen oxides from the air (thermal NOx). The location of the injection holes and the mixing of the supercharged air are crucial to maintain efficient combustion [11].

\section{Experimental task}

The FLOREAN application software package was used to perform numerical simulation of heat and mass transfer processes during the combustion in the furnace chamber of the boiler BKZ 75-39FB Shakhtinskaya CHP [12-14]. This programme takes into account all the real conditions of the process under study: the technical parameters of the boiler, the physical characteristics of the fuel, the mechanism of fuel combustion, the processes of heat and mass transfer, the mathematical formulation of the problem and chemical transformations that occur at high temperatures.

Numerical studies of heat and mass transfer processes were carried out using three-dimensional equations of convective heat and mass transfer taking into account convective and radiative heat transfer, chemical kinetics, and two-phase nature of the medium. All these nonlinear equations include the law of conservation of mass, the law of conservation of momentum (Navier-Stokes equation), the law of conservation of energy and the law of conservation of matter [15-18].

In this study, the object of study was the furnace chamber of the boiler BKZ-75-39FB, located at the thermal station of the city of Shakhtinsk in Kazakhstan. The installed thermal capacity of the power plant is $144 \mathrm{Gcal} / \mathrm{h}$, and the electric capacity is $18 \mathrm{MW}$. Currently, the existing main equipment includes 3 power boiler units BKZ-75-39FB and 2 turbine units PR-6-35-5/1,2.

The combustion of pulverized coal fuel in the furnace chamber of the boiler BKZ is carried out using four pulverized coal burners, two located on each side wall. 
Shakhtinskaya CHPP has the ability to operate on fuel oil, as a result of which approximately 44.256 thousand tons of coal and 4.15 thousand tons of fuel oil are burned per year on one boiler of the thermal station. The amount of mechanical underburning from the combustion of pulverized coal fuel at BKZ-75 is $13.37 \%$. Fuel combustion schemes are chosen depending on the brand and quality of fuel. The boiler unit BKZ 75of Shakhtinskaya CHP incinerates the dust of Karaganda ordinary coal of the KR-200 brand, having an ash content of $35.1 \%$, a volatile yield of $22 \%$, a humidity of $10.6 \%$ and a heat of combustion of $18550 \mathrm{~kJ} / \mathrm{kg}$. The grinding thickness of coal is $\mathrm{R}_{90}=20 \%$. The composition of the used Karaganda coal includes carbon $43.21 \%$ (C), hydrogen $3.6 \%\left(\mathrm{H}_{2}\right)$, oxygen $5.24 \%\left(\mathrm{O}_{2}\right)$, sulfur $1.04 \%\left(\mathrm{~S}_{2}\right)$, nitrogen $1.21 \%\left(\mathrm{~N}_{2}\right)$, water $10.6 \%$ $\left(\mathrm{H}_{2} \mathrm{O}\right)$ and ash $35.1 \%$ (A). When conducting computational experiments, the value of the excess air coefficient at the outlet of the furnace chamber of the boiler BKZ 75-39FB, operating on s olid pulverized coal fuel with steam capacity $\mathrm{D}=75 \mathrm{t} / \mathrm{h}$ is assumed to be equal to $\alpha=1.2$.

At the initial stage of the computer experiment on the combustion of pulverized coal fuel in the furnace chamber of the boiler BKZ 75-39FB using the fuel combustion technology "Overfire air", it is necessary to construct the geometry of the boiler under study, as well as to obtain its finite-difference grid. In addition, in the PREPROZ software package used, it is necessary to create source files containing physical and geometric information of the process under study, as well as initial and boundary conditions for modeling the process of heat and mass transfer in turbulent high-temperature flows.

As a result, the boiler was divided into 455040 control volumes. Figure 1 shows the breakdown of the boiler of the BKZ 75-39FB of the Shakhtinskaya CHPP into control volumes and the location of the burner devices and the OFA injectors being introduced.

During the experiment, various ways of supplying additional air through OFA nozzles were investigated:

-OFA $=0 \%$ (basic version without additional air supply),

-OFA $=10 \%$ and

$-\mathrm{OFA}=18 \%$.

For these three modes, a comparative analysis of the aerodynamics of the furnace part of the boiler was performed according to the obtained distributions of the temperature and concentration fields of nitrogen oxide $\mathrm{NO}$ over the entire volume of the combustion chamber.

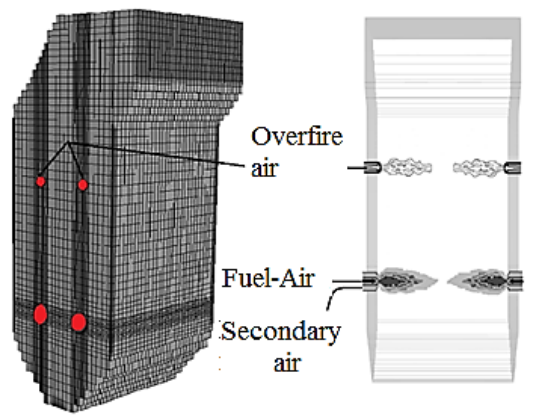

Fig. 1. Breakdown of the boiler for control volumes and arrangement of burners and injectors OFA

\section{Computational experiments results and discussion}

As a result of a computer experiment, temperature distributions were obtained for the control volumes and the location of burners and injectors OFA (Figure 2) in the area of the burner devices for the base case of OFA $=0 \%$ and the case of "sharp blast" $(\mathrm{OFA}=10 \%$ and $\mathrm{OFA}=18 \%)$.

a) $\mathrm{OFA}=0 \%$
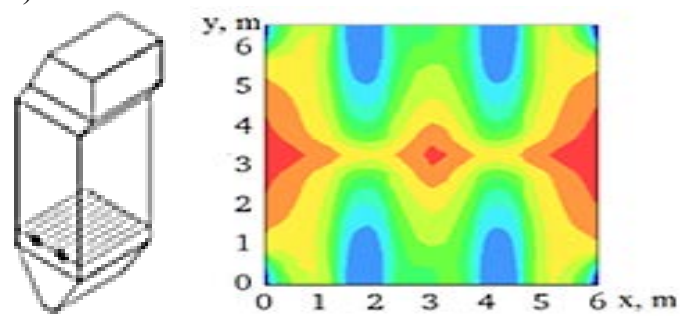

b) $\mathrm{OFA}=10 \%$
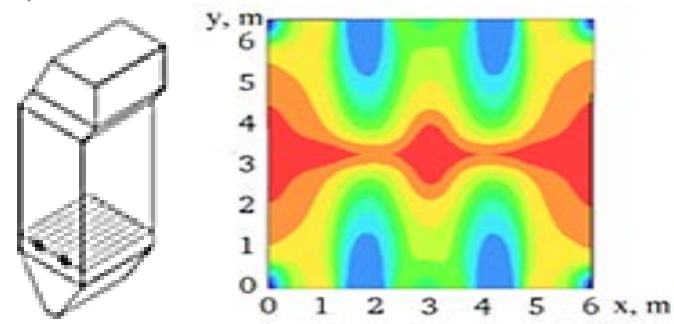

c) $\mathrm{OFA}=18 \%$
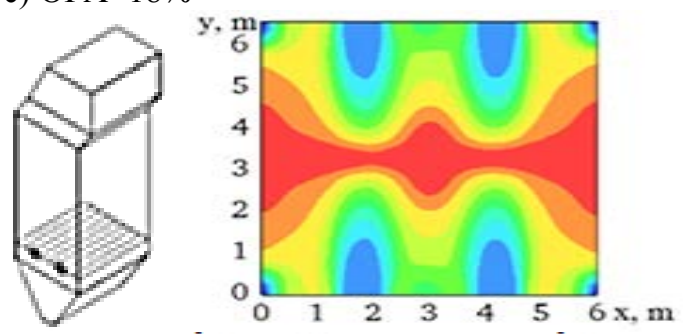

Temperature, ${ }^{\circ} \mathrm{C}$

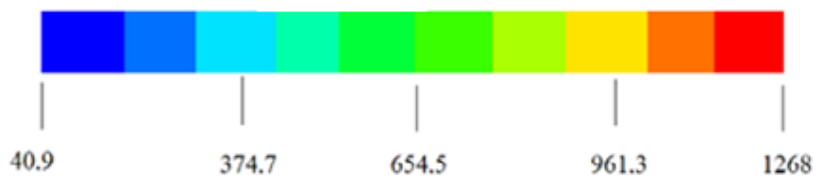

Fig. 2. Temperature distribution in the burner area for different volumes of additional supplied air 
Analysis of this distribution shows that with an increase in the volume of air supplied through the OFA injectors, the temperature in the center of the combustion chamber increases.

For the initial case of $\mathrm{OFA}=0 \%$, the temperature in the center of the furnace chamber was $620.6{ }^{\circ} \mathrm{C}$; with the introduction of OFA injectors, i.e. by supplying additional air in the volume of $10 \%$ of the total amount of air supplied, the temperature increased to $750.3{ }^{\circ} \mathrm{C}$, and as a result of the third case, OFA $=18 \%$, the temperature became 754.1 ${ }^{\circ} \mathrm{C}$.

In the area of the OFA injectors, the temperature on the contrary decreased (Figure 3) with an increase in the volume of air supplied: for the base case, OFA $=0 \%-987.3{ }^{\circ} \mathrm{C}$; OFA $=10 \%-918.6{ }^{\circ} \mathrm{C}$ and for the case of OFA $=18 \%-879.2{ }^{\circ} \mathrm{C}$.

a) $\mathrm{OFA}=0 \%$
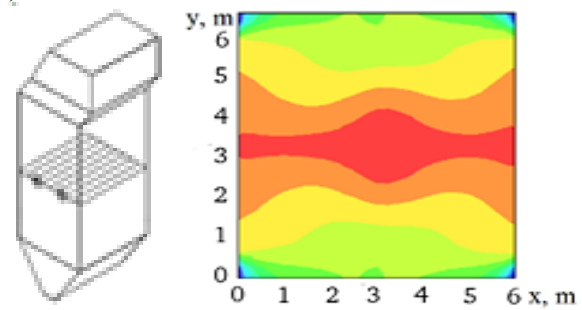

b) $\mathrm{OFA}=10 \%$
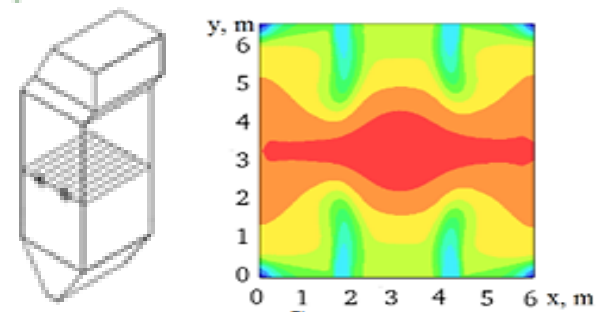

c) $\mathrm{OFA}=18 \%$
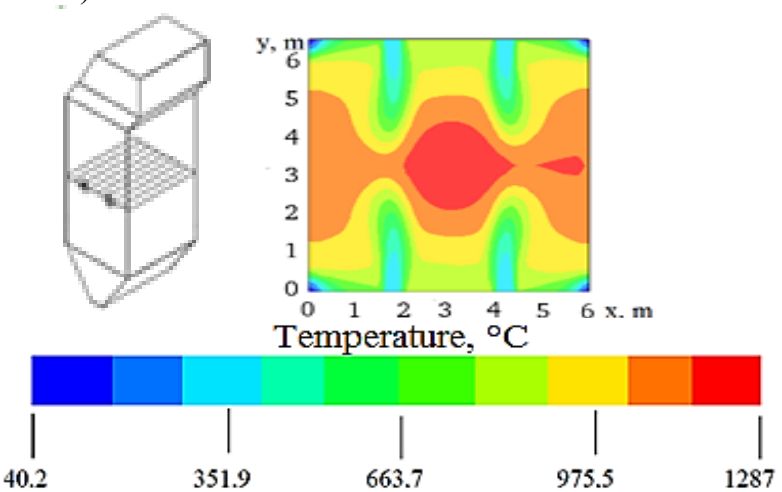

Fig. 3. Temperature distribution in the area of the OFA injectors for different volumes of additional supplied air

This temperature behavior is clearly seen in Figure 4 , which shows the distribution of the combustion temperature $(\mathrm{T})$ over the height of the boiler BKZ 75-39FB for various volumes of air supplied through the OFA nozzles. At the exit from the combustion chamber, we still have a decrease in temperature. In the base case (OFA $=0 \%)$, the temperature is kept at $885.80{ }^{\circ} \mathrm{C}$. Introducing additional air injectors OFA $=10 \%$ - the temperature drops to $865.91{ }^{\circ} \mathrm{C}$, and at OFA $=18 \%$ - it becomes $856.27^{\circ} \mathrm{C}$.

The temperature at the outlet of the combustion chamber is confirmed by experimental data obtained directly at the thermal power plant [19] and its theoretical value calculated by the CCTI method [20] for the base case.

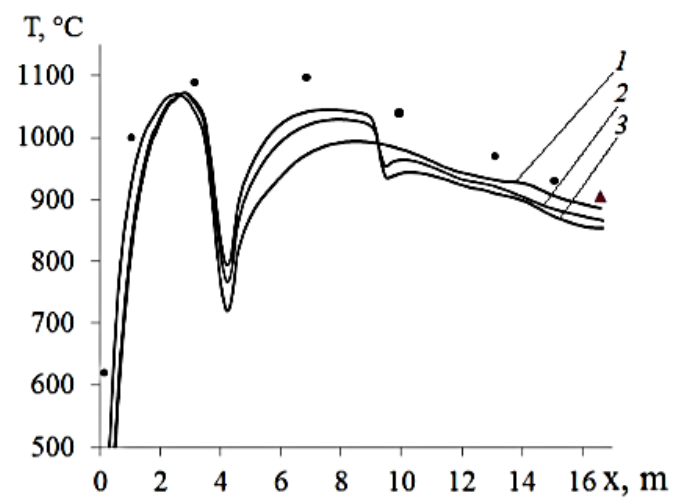

Fig. 4. Temperature distribution (T) along the height of the combustion chamber of the boiler BKZ 7539FB at different volumes of air supplied through the OFA injectors:

$1-\mathrm{OFA}=0 \%, 2$ - OFA $=10 \%, 3-\mathrm{OFA}=18 \%$;

$\Delta$ - experiment at thermal power plant [19];

- - theoretical value obtained by the CCTI method [20]

Distribution of the concentration of nitrogen oxide NO in the area of the burner devices and OFA injectors along the height of the combustion chamber for three options additional air supply: a) $\mathrm{OFA}=0 \%$ (basic version), b) $\mathrm{OFA}=10 \%$, c) OFA $=18 \%$ is shown in Figures 5-7.

a) $\mathrm{OFA}=0 \%$
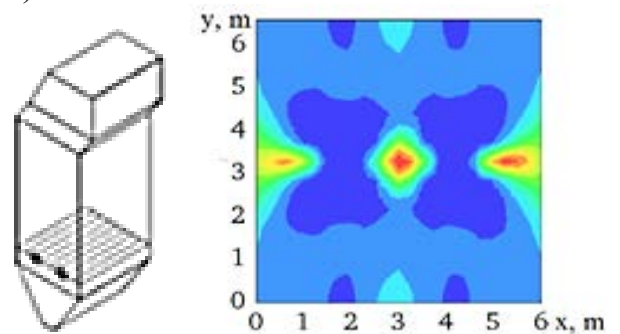

b) $\mathrm{OFA}=10 \%$
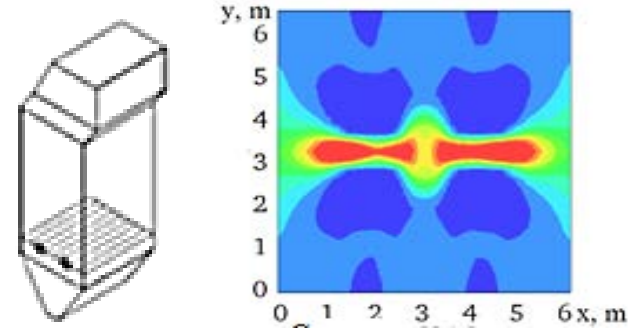
c) $\mathrm{OFA}=18 \%$
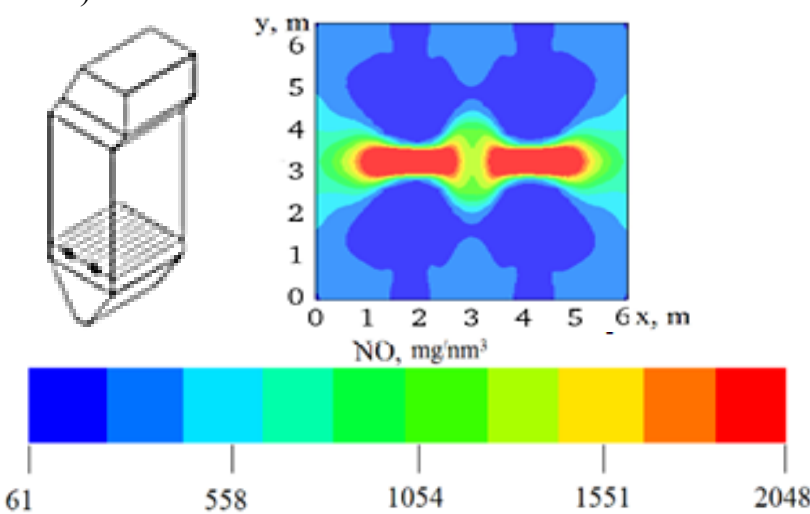

Fig. 5. Distribution of NO nitric oxide concentration in the burner location area for different volumes of air supplied through OFA injectors

a) $\mathrm{OFA}=0 \%$
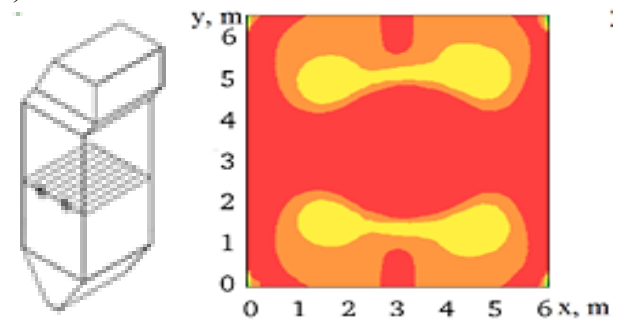

b) $\mathrm{OFA}=10 \%$
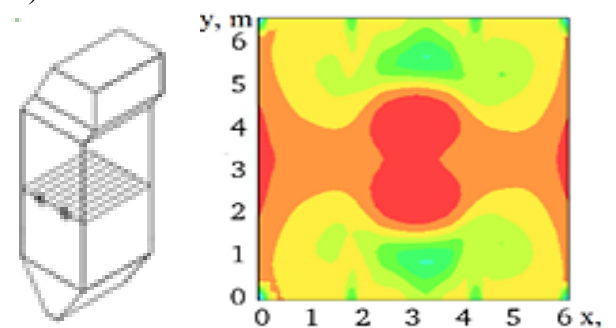

c) $\mathrm{OFA}=18 \%$
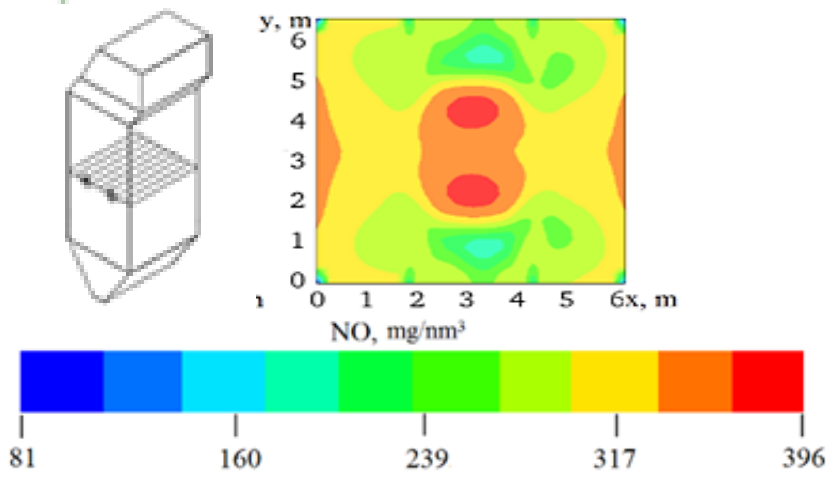

Fig. 6. Distribution of NO nitric oxide concentration in the area of the OFA injectors for different volumes of air supplied through OFA injectors

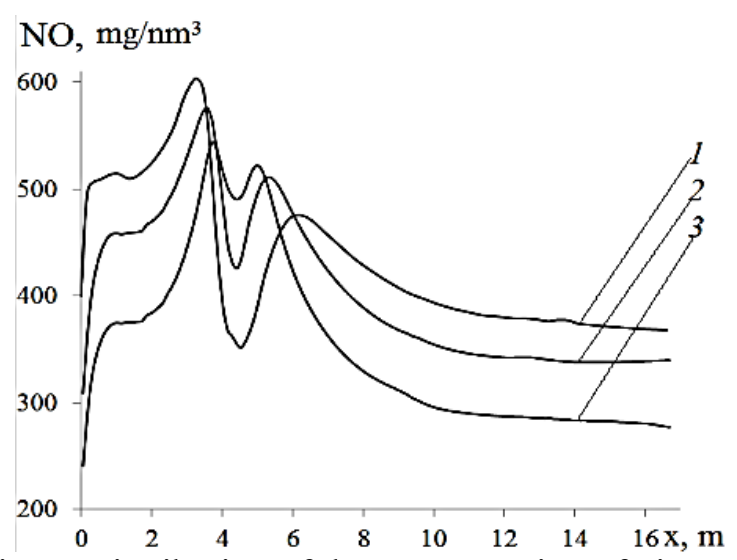

Fig. 7. Distribution of the concentration of nitrogen oxide NO by the height of the combustion chamber of the boiler at different volumes of air supplied through the OFA nozzles:

$1-\mathrm{OFA}=0 \%, 2-\mathrm{OFA}=10 \%, 3-\mathrm{OFA}=18 \%$

Studies show that the introduction of OFA technology on the boiler BKZ 75-39FB leads to a change in the distribution of temperature $\mathrm{T}$ and concentrations of nitrogen oxide NO in the furnace space. The results presented in these figures show that an increase in the volume of air supplied through OFA injectors reduces the concentration of harmful emissions of nitrogen oxides NO.

The supply of additional air in the case of OFA = $18 \%$ is the optimal mode for the combustion chamber of the boiler BKZ 75-39FB: at the outlet of the combustion chamber we have a concentration of nitrogen oxide NO equal to $277.12 \mathrm{mg} / \mathrm{nm}^{3}$, which is $24.7 \%$ lower than the base case (OFA $=0 \%$ ), when the concentration of nitrogen oxide is 368.08 $\mathrm{mg} / \mathrm{nm}^{3}$.

Thus, it can be concluded that the Overfire air "sharp blast" technology is one of the perspective ways to reduce the amount of emissions of harmful substances (nitrogen oxides NOx), and its introduction at coal-fired thermal power plants (in particular, at the boiler BKZ 75-39FB Shakhtinskaya CHP) can have a significant positive impact on the environment.

\section{Conclusion}

The proposed work is devoted to the study of methods for reducing emissions of harmful substances into the environment and the study of physico-chemical processes occurring in the furnace chamber of the boiler BKZ 75-39FB of a real energy facility located in the Republic of Kazakhstan. The results of computational experiments on $\mathrm{t}$ he introduction of "sharp blast" technology or "Overfire air" technology were obtained in the work. 
During the computer experiment, a comparative analysis of changes in the main characteristics (temperature $\mathrm{T}$ and concentrations of nitrogen oxides NO) was carried out with the introduction of step-by-step combustion technology (OFA). It is shown that the values of temperatures and concentrations of $\mathrm{NO}$ most accurately describe the data of a real experiment.

As a result of the experiment, it was shown that the main difference in the temperature field is achieved in the area of active combustion. With an increase in the mass flow of air through the OFA nozzles, the average temperature in the area of the location of the torch core increases, and in the area of the location of the OFA injectors decreases. However, by the exit from the furnace chamber, the temperature differences do not exceed $30^{\circ} \mathrm{C}$, as a result, this decrease is insignificant.

The main result of the study is a decrease in the concentrations of nitrogen oxides NOx due to the use of "sharp blast" technology. The paper shows that the most intensive formation of nitrogen oxides occurs in the area of the flow propagation from the burner devices, i.e. in the area of active combustion, which corresponds to the real picture of the process in the furnace chamber.

At $\mathrm{OFA}=18 \%$, a concentration of nitrogen oxide $\mathrm{NO}$ is formed at the outlet of the combustion chamber equal to $277.12 \mathrm{mg} / \mathrm{nm}^{3}$, which is $24.7 \%$ lower than the base case (OFA $=0 \%$ ), when the concentration of nitrogen oxide is $368.08 \mathrm{mg} / \mathrm{nm}^{3}$.

Since the single maximum permissible concentration (MPC) for emissions of nitrogen oxides NO in the Republic of Kazakhstan is 367 $\mathrm{mg} / \mathrm{nm}^{3}$, this allows us to conclude that the innovative solutions proposed in this paper are applicable in real energy facilities of the industry of the Republic of Kazakhstan.

\section{References:}

[1] Askarova A.S., Safarik P., Bolegenova S.A., etc., Combustion processes of pulverized coal in existing combustion chambers of real power boilers of TPP of the Republic of Kazakhstan, Mat. of the 23rd International Congress of Chemical and Process Engineering (CHISA 2018), 2018, pp.437-452.

[2] Möltner L., Schallhart V. Numerical optimization of AdBlue $\AA$-injection into the mixing section of SCR-systems, WSEAS Transactions on Fluid Mechanics, Vol.10, 2015, pp.80-87.

[3] Beketayeva M.T., Ospanova Sh., Gabitova Z., etc., Investigation of turbulence characteristics of burning process of the solid fuel in BKZ 420 combustion chamber, WSEAS Transactions on Heat and Mass Transfer, Vol.9, 2014, pp.3950.

[4] Maximov V., Ergaliyeva A., Gabitova Z., etc., Three-dimensional modelling of heat and mass transfer during combustion of low-grade Karaganda coal, Mat. of the 19th Conference on Process Integration, Modelling and Optimisation for Energy Saving and Pollution Reduction (PRES 2016), 2016, pp. 0734.

[5] Mele J., Oman J., Krope J., Scale-up of a Cold Flow Model of FICFB Biomass Gasification Process to an Industrial Pilot Plant Hydrodynamics of Particles, WSEAS Transactions on Fluid Mechanics, Vol.5, 2010, pp.15-24.

[6] Hill C., Smoot L.D., Modeling of nitrogen oxides formation and destruction in combustion systems, Mat. of the Int. Conf. «Prog. in Energy and Combustion Science», Vol.26, 2000, pp. 417-458.

[7] Li Z., Miao Zh., Primary air ratio affects coal utilization mode and NOx emission in lignite pulverized boiler, Energy, Vol.187, 2019, pp. 116-123.

[8] Liu G., Zhu Q., Li Zh., Zhu X., Chen Z., New over-fire air arrangement and its air ratio optimization determined by aerodynamic characteristics in a cold small-scale model for a down-fired 660-MWe utility boiler, Experimental Thermal and Fluid Science, Vol.44, 2013, pp.475-482.

[9] Liu G.K., Zhu Q.Y., Zhu X.Y., Effect of overFire Air Velocity on the Aerodynamic Characteristics in a Cold Model of an ArchFired Boiler with New over-Fire Air Arrangement, Advanced Materials Research,Vol.610-613, 2012, pp.1416-1421.

[10] Singer S., Pulverized coal combustion, Noyes Publications, 1984.

[11] Smoot L.D., Pulverized Coal Diffusion Flames: A perspective through the modeling, Works of $18^{\text {th }}$ Symposium on Combustion, 1981, pp.1185-1202.

[12] Maximov V.Ju., Bekmuhamet A., Beketayeva M.T., etc., Analysis of formation harmful substances formed as a result of burning the low-grade coal in the combustion chamber of the industrial boiler of Kazakhstan using CFDcode FLOREAN, Mat. of the 17th Conference on Process Integration, Modelling and Optimisation for Energy Saving and Pollution Reduction (PRES 2014), 2014, pp. 7.160. 
[13] Muller H., Leithner R., Combustion of lowrank coals in furnaces of Kazakhstan coalfiring power plants, VDI Berichte, 2007, pp.497-502.

[14] Heierle Y., Leithner R., Müller H., Askarova A., CFD Code FLOREAN for Industrial Boilers Simulations, WSEAS Transactions on Heat and Mass Transfer, Vol.4, No4, 2009, pp. 98-107.

[15] Askarova A., Bolegenova S., Bekmukhamet A., etc., Computational method for investigation of solid fuel combustion in combustion chambers of a heat power plant, High Temperature, Vol.53, 2015, pp.751-757.

[16] Epple B., Leithner R., Linzer W., Walter H., Simulation von Kraft werken und warmetechnischen, Springer, 2009.

[17] Cannata G., Barsi L., Tamburrino M., A 3D Numerical Model for Turbidity Currents, WSEAS Transactions on Fluid Mechanics, Vol.15, 2020, pp.1-12.

[18] Bolegenova S.A., Askarova A.S., Beketayeva M.T., etc., Modeling of heat mass transfer in high-temperature reacting flows with combustion, High Temperature, Vol.56, 2018, pp.738-743.

[19] Khmyrov V.I., Obrabotka i vnedreniye tekhnologiy stupenchatogo szhiganiya topliva so snizheniyem vykhodov okislov azota na 3040\%, dlya kotlov PTVM-100, BKZ-420, BKZ160. Kaz NIIE. Otchet, Report №287942, 1990.

[20] Thermal calculation of boilers: Normative method, CCTI, 1998.

\section{Contribution of individual authors to the creation of a scientific article (ghostwriting policy)}

Aliya Askarova, Saltanat Bolegenova has organized and executed the experiments.

Symbat Bolegenova, Valeriy Maximov and Meruyert Beketayeva carried out the simulation results, interpretation (discussion) and verification of results.

Follow: www.wseas.org/multimedia/contributorrole-instruction.pdf

\section{Sources of funding for research presented in a scientific article or scientific article itself}

Research funded by the Ministry of Education and Science of the Republic of Kazakhstan

\section{Creative Commons Attribution \\ License 4.0 (Attribution 4.0 \\ International , CC BY 4.0)}

This article is published under the terms of the Creative Commons Attribution License 4.0 https://creativecommons.org/licenses/by/4.0/deed.en US 